\title{
EDITORIAL
}

\section{Publish (negative results too) or perish}

\section{Publique (resultados negativos também) ou pereça}

\author{
Eduardo Melani Rocha², Mario Luiz Ribeiro Monteiro²
}

Over the past decades, the quotation "publish or perish" has been echoing in the minds of everyone with an academic carrier. The good will behind these three words is that science is a public task, science does not have frontiers, and science grows better with multiple and interdisciplinary collaboration. Meanwhile, not ensuring a certain amount of hype about the product of a scientific task is the same as condemning it to death. Furthermore, publication of research results is considered an obligation that the researcher has to the society, the university to which he/she belongs to, and the research agency supporting the studies.

Everything is perfect until someone gets "negative results," when the above-mentioned rationale is disrupted. Let us define negative results before continuing further. Negative results are data collected from a well-designed project, well-performed assays, and from analyses that do not confirm the hypothesis of the study. This leads the researcher to accept the "null hypothesis" $(\mathrm{H} 0)$, indicating that there is no relationship between the two measured phenomena, or from a statistical point of view, showing that the probability of the phenomena occurs by chance and not because the intervention is above the adopted significance level (p, usually 5\%). A simple example in ophthalmic research is when the benefit of treatment with a placebo is similar or superior to that treatment with the drug being tested, with a comparison of the mean outcome measurements resulting in a p-value of $\geq 0.05$ or $5 \%$. In this example, the study accepted the null hypothesis when concluded that the drug being tested was not more efficient than the placebo. The scientific community would label this study a "negative result" study.

In the scientific world, a negative result leads to disappointment in the research group involved in the study, followed by displeasure of the agency or company involved in the financial support, and worst of all, skepticism and disinterest of reviewers and editors of scientific journals. The final result of the process is hidden, buried data, thus, ignored by the scientific community ${ }^{(1)}$. Interestingly and ironically, in journalism, there is a general interest in bad (or negative) news, whereas good news is usually only briefly (or not) reported.

However, in science negative results should not be treated in a negative way. Although we may understand the journalistic interest for bad news to gain public attention, we should not accept that only positive research results are worthy because they tend to gain attention from medical journals (and their reviewers). Negative results in science may represent the result of significant time and money spent to obtain them. The cost of not announcing them properly may lead to greater expenditure when other scientific groups repeat the work. Scientific community will ignore the previous effort because they had never been published. The efforts of authors who had obtained negative results must be credited and not labeled as failure or bad planning. Moreover, negative results give a balance for comparing potential therapeutic approaches in systematic reviews and meta-analysis. Hidden negative results only nourish the unacceptable interests of those who benefit from these results being hidden. Most importantly, negative results may imply that a new (and usually expensive) drug or technology does not add significant advantage over well-established ones. This information may save time and money for patients and the society, not to mention avoiding previously unknown side effects that usually are discovered only after new drugs are released. In some situations, negative results may in fact be the good results, and reporting them may avoid unnecessary treatments, testing, or surgeries.

In their most recent book, "Think like a freak," Steven D. Levitt and Stephen J. Dubner quote the former New York mayor Michael Bloomberg: "In medicine and science, if one follows a path that reveals a dead end, it will have taken a relevant contribution, because we know that it will not be accurate to travel the same path"(2). Efforts to revert the practice of aversion to negative results are being made by the biomedical community. Among those efforts are the clinical trials registers ${ }^{(3)}$. Their objective is to announce every clinical trial prior to initiating data collection from patients. Data will be known to the registers, despite the results being unfavorable for the sponsors supporting the studies. Another effort is made by scientific journals, whose name and mission reinforce the commitment to judge and publicize negative results; such journals include Journal of Negative Results in Biomedicine, the Journal of Negative Results-Ecology and Evolutionary Biology, and the Journal of Articles in Support of the Null Hypothesis ${ }^{(4)}$.

Submitted for publication: February 7, 2015 Accepted for publication: February 7, 2015

${ }^{1}$ Department of Ophthalmology, Otorhinolaryngology and Head and Neck Surgery, Ribeirão Preto Medical School (FMRP), University of São Paulo (USP), Ribeirão Preto, SP, Brazil.

2 Department of Ophthalmology and Otorhinolaryngology, School of Medicine, University of São Paulo (USP), São Paulo, SP, Brazil.
Funding: No specific financial support was available for this study.

Disclosure of potential conflicts of interest: None of the authors have any potential conflict of interest to disclose.

Corresponding author: Eduardo M. Rocha. Av. Bandeirantes, 3.900 - FMRP-USP - 14049-900 Ribeirão Preto - SP - Brazil - E-mail: emrocha@fmrp.usp.br 
In the midst of the pressure to publish study data and the low priority given by major journals to articles with negative results, academic researchers are faced with another nightmare, the so-called "predator journals." As pointed out by Jeffrey Beall, predator journals proceed with a list of misconducts that jeopardize the reputation of their authors and the patience of their readers and scientific community. For example, they do not follow the ethical principles of open access journals, do not use ISSN or DOI numbers, and worse, falsely claim to have an impact factor or use some informal measures (e.g., estimated factor or view factor). These journals frequently use spam messages, alleging to have a motto to serve the scientific community while focusing on receiving author fees for publication with an average charge of approximately US\$2000 $(5,6)$. It is easy to predict that authors with negative results are frequent victims of such journals, but they must be aware that this practice may compromise their carriers instead of pushing them up. Recent scandals noticed in the press revealed that some of these journals clearly do not have peer reviews or any reviews at all. Manuscripts generated by a robotic word processor or made up by one single phrase repeated throughout the entire text were published as scientific papers in two of these journals ${ }^{(7)}$.

Instead of giving in to the temptation of publishing in predator journals or not publishing their results, researchers with negative results should instead learn how to emphasize the importance of their studies both in the rationale and in the discussion of their papers and present it to peer-reviewed journals with a clear editorial commitment to ethics and honest science. ABO - Arquivos Brasileiros de Oftalmologia reinforces the editorial line to publish original papers in the field of ophthalmology with good scientific quality, whether the results confirm or disprove the study hypothesis, because both types of results are useful and required to have a good understanding of scientific questions in order to guide readers in their clinical practice and future research. Publication of negative results is necessary to prevent the credibility of the scientific community from perishing.

\section{REFERENCES}

1. Lexchin J, Bero LA, Djulbegovic B, Clark O. Pharmaceutical industry sponsorship and research outcome and quality: systematic review. BMJ. 2003;326(7400):1167-70.

2. Levitt SD, Dubner SJ. Think like a freak. New York: HarperCollins Publishers; 2014

3. National Institute of Health. Clinical trials register. Washington, DC; NIH. [cited 2015 Jan 29]. Available from: https://clinicaltrials.gov/

4. O'Hara B. Negative results are published. Nature. 2011;471(7339):448-9. Comment on: Nature. 2011;470(7335):437.
5. Beall J. Criteria for determining predatory open-access publishers. Scholary Open Access: critical analysis of scholarly open-access publishing. [cited 2015 Jan 29]. Available from: http://scholarlyoa.com/2012/08/04/criteria-for-determining-predatory-open-accesspublishers/

6. Butler D. Investigating journals: The dark side of publishing. Nature. 2013;495(7442): 433-5.

7. Schwartsman H. Brincando com a ciência. Folha de São Paulo [Internet]. 2015 Jan 03. [cited 2015 Jan 29] Disponível em: http://www1.folha.uol.com.br/colunas/heliosch wartsman/2015/01/1569975-brincando-com-a-ciencia.shtml

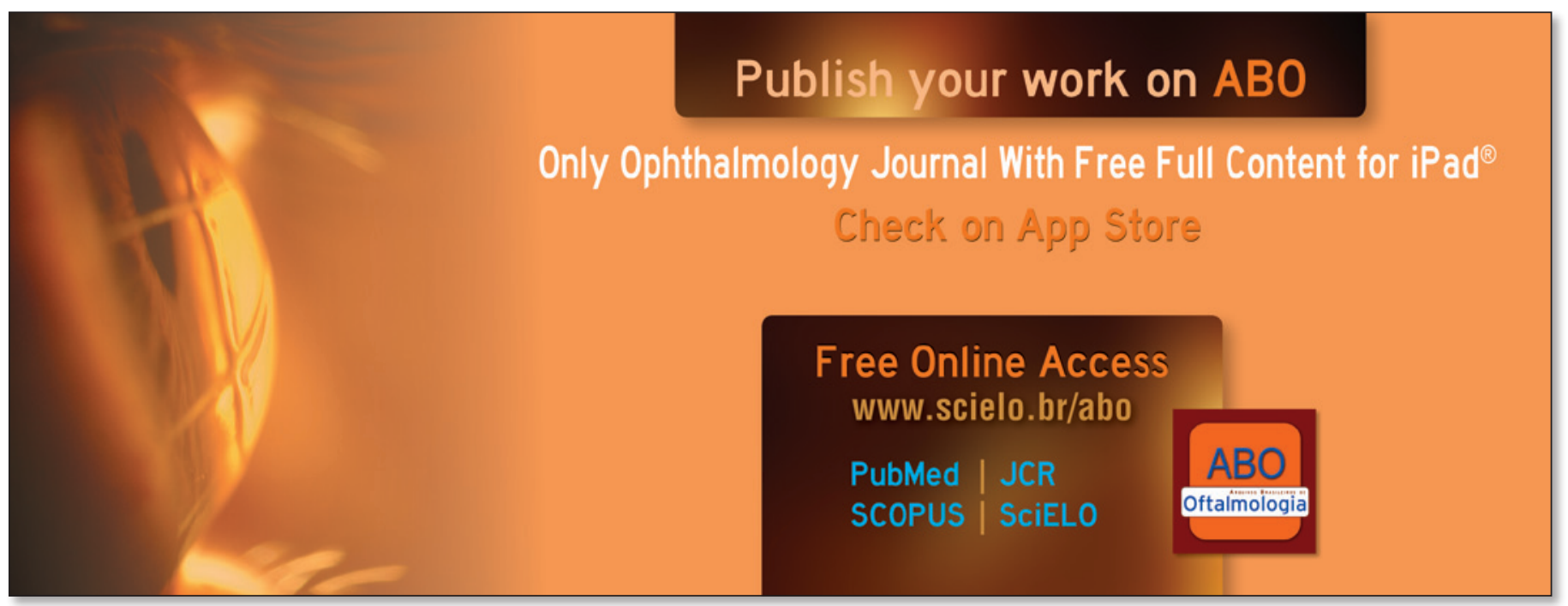

